\title{
O Movimento dos Trabalhadores Rurais Sem Terra (MST) na atualidade: luta, organização e educação
}

Entrevista concedida por Álvaro Santin*, da coordenação nacional do Movimento dos Trabalhadores Rurais Sem Terra (MST), a Célia Regina Vendramini e a Sonia Maria Rummert, 12 de novembro de 2007, Florianópolis - SC.

Palavras-chave: Santin, Álvaro. Entrevistas. Movimentos Sociais Rurais.

Revista Perspectiva - Gostaríamos que nos falasse um pouco a respeito do contexto atual em que se situam os movimentos sociais, especialmente o MST; o que mudou na cena política e econômica, quais os entraves, quais os desafios atualmente enfrentados pelo Movimento?

Álvaro Santin - Vivenciamos, em nível nacional, um descenso das lutas sociais com a eleição do governo Lula, em relação ao qual havia uma grande esperança com relação às mudanças. Isso decepcionou vários segmentos sociais organizados, alguns setores foram cooptados, outros se desiludiram com a política, outros se acomodaram, outros mudaram de lado... O MST procurou se manter coerente com os objetivos da luta pela terra, da luta pela Reforma Agrária e pela transformação social; no entanto, continuamos enfrentando um estado burguês que favorece o agronegócio, que favorece o mercado externo e as grandes empresas. Obtivemos conquistas sociais como a moradia, a assistência técnica, a melhoria das nossas estruturas sociais e a melhoria das infra-estruturas, melhorias essas que são permitidas dentro da estrutura capitalista. Porém, no que tange ao enfrentamento do modelo econômico, que se dá principalmente com a destinação de terras para a reforma agrária, pouco se avançou. Sairam algumas áreas de terras para assentamento, mas o latifúndio continua intacto e com mais força. A concentração, a acumulação capitalista no campo aumentou enormemente pelo setor de geração de energia (madeira, biodiesel, minérios, barragens). Diminuiu a miséria com os programas sociais, mas a concentração de riqueza aumentou; o País não precisa

* Agrônomo pela Universidade Central de Las Villas, Santa Clara, Cuba. Diretor do Movimento dos Trabalhadores Rurais Sem Terra-Santa Catarina. Dirigente das Cooperativas de Reforma Agrária - Santa Catarina. Chapecó-SC.E-mait. alvaro@mst.org.br 
somente de distribuição de renda, precisa distribuir as riquezas acumuladas, riquezas que pertencem ao povo brasileiro.

Revista Perspectiva - Como o MST tem respondido a tais mudanças, como tem enfrentado o atual contexto: houve mudanças em seus objetivos e planos, em suas estratégias, em suas formas de luta? E quanto a seus aliados, como está o quadro atual?

Álvaro Santin - Trabalhamos em uma perspectiva de acumularmos forças. Nesse sentido, buscamos melhorar, dentro do possível, as condições de vida das familias assentadas, desenvolvemos um amplo processo para elevar o nível de conhecimento e de consciência da nossa base, através de cursos de formação e de capacitação. Desenvolvemos práticas de cooperação para visualizar um novo modo de vida no campo brasileiro, nos articulamos e contribuímos com outros setores sociais para se somarem à luta da Reforma Agrária, pois entendemos que essa é uma luta de toda a sociedade, que sozinhos não vamos alcançá-la e somente acontecerá quando houver de fato transformações sociais.

Nós somamos na luta de outros trabalhadores, como foi o caso, aqui em Santa Catarina, dos trabalhadores mineiros e químicos de Criciúma, dos trabalhadores públicos de Blumenau, dos servidores públicos estaduais da educação, transporte, entre outros; Além, é claro, da articulação da Via Campesina, que envolve os movimentos do campo. Continuamos ocupando o latifúndio, enfrentamos o exército na área da União em Papanduva (SC), enfrentamos o governo do Estado na área da EMBRAPA cedida à EPAGRI, em Caçador ( $\mathrm{SC}$ ), e ocupamos mais quatro áreas de outros latifúndios ano passado.

Nos assentamentos, buscamos concentrar nossos esforços no sentido de construir, na prática, um novo modelo de desenvolvimento, no qual de fato o tema cumpra sua função social, no qual se produzam alimentos, e não mercadorias, no qual o camponês seja um produtor de alimentos, de conhecimento, e não meramente consumidor de tecnologias, insumos ou mesmo de alimentos, no qual se desenvolva, no campo, um novo modo de vida baseado na cooperação, na solidariedade, com novos valores. Que se produzam alimentos, mas que se consigam viabilizar práticas de agroindustrialização e de comercialização diferentes. Buscamos construir espaços sociais tanto para desenvolver uma nova cultura, como espaços de educação do campo onde se 
respeite a realidade dos camponeses e que, ao mesmo tempo, ajudem a superar o atraso que às vezes está encalacrado em um aculturamento prejudicial ao novo homem e à nova mulher que queremos construir.

Revista Perspectiva - Como se configura, atualmente, a base do MST? Continua a mesma? Houve alterações? De que tipo?

Álvaro Santin - O MST, em Santa Catarina, conta com aproximadamente 6.000 familias assentadas e em torno de 800 familias acampadas; em nível nacional, são 350.000 familias. Aqui no Estado, vivenciamos a segunda geração dos Sem-Terra, muitas das nossas crianças que nasceram nos acampamentos e assentamentos, hoje são a nossa juventude que atua internamente na organização, que participa dos espaços de formação e capacitação das nossas escolas e também participa da luta pela terra e da luta pela transformação social. Buscamos garantir que a luta pela terra seja a luta da familia Sem-Terra. Nesse sentido, é fundamental a participação dos homens, mulheres, da juventude e das nossas crianças. Desenvolvemos atividades com toda esta base, mas também especificamente com as mulheres, jovens e crianças, mas todos inseridos no MST; não é uma política à parte, e sim dentro da própria organização.

Acredito que a principal alteração é a presença da juventude, que é muito grande e que está se inserindo organicamente na vida do MST. Para isso, temos que garantir que eles tenham participação ativa na construção dos rumos do movimento.

Revista Perspectiva - Quais os atuais planos e ações do MST para a organização dos assentamentos e cooperativas, diante das dificuldades do modelo de cooperação implantado nos assentamentos na década de 1990?

Álvaro Santin - A cooperação é vista, dentro do MST, como uma forma de resistência ao atual modelo agrícola e econômico. Sabemos que dificilmente a pequena propriedade ou o camponês isolado vai sobreviver se não praticar algumas formas de cooperação. Mas a cooperação também aponta para o novo, para a construção de um novo modelo produtivo, para um novo modo de vida no campo. Possibilita desenvolver, na prática, novos valores que têm no ser humano sua centralidade e prioridade, e não no dinheiro, no lucro ou no mercado. 
Enfrentamos muitas dificuldades em desenvolver formas de cooperação mais complexas como as da socialização da terra, dos meios de produção, da vivência em coletivo; no entanto, não paramos de desenvolver essas formas de cooperação. Mas trabalhamos com todas as formas de cooperação; o importante é desenvolver a cooperação até mesmo do ponto de vista pedagógico. Incentivar as diferentes formas, desde as mais simples, nas quais se tem mais facilidade de participar, mas que, ao mesmo tempo, está se deixando de desenvolver. Vivenciamos um período no qual se reforça, em nivel de país, o modelo capitalista na agricultura; conseqüentemente, os valores do capital vêm embutidos; é a concorrência, a competitividade, o individualismo, valores altamente nocivos à prática da cooperação. Portanto, o momento é desfavorável à cooperação.

Avançamos nas formas de cooperação onde se industrializa a produção dos assentamentos. Hoje, são várias cooperativas do MST que estão nessa área e agregam um maior número de famílias Sem-Terra. Resultado: isso possibilitou desenvolver uma marca dos produtos da Reforma Agrária, que é a marca Terra Viva, e dar visibilidade à produção dos assentamentos.

Atualmente, trabalhamos nas diferentes regiões do Estado dentro de uma estratégia produtiva na qual estão sendo priorizadas algumas linhas de produção para geração de renda para as famílias assentadas. Ao mesmo tempo, trabalhamos para que se resgate o papel da agricultura, que é produzir alimentos, e não mercadoria, além da uma auto-sustentação, que respeite o meio ambiente e produza alimentos para uma vida saudável.

Revista Perspectiva - A história mostra que, em momentos difíceis, a tendência é de uma aposta muito grande na questão educacional e escolar, atribuindo a ela papel central. Como a questão educacional aparece para o MST? Ela tem sido um elemento na luta pela transformação social ou pode ser uma forma de canalizar as dificuldades no campo econômico e da organização social? Quais as diferenças básicas entre as concepções de educação defendidas e implementadas pelo MST e aquelas que, atualmente, são defendidas e implementadas pelas forças dominantes?

Álvaro Santin - Temos construído, dentro do MST, uma boa concepção do que queremos e sobre o tipo de educação de que precisamos para o conjunto do MST e, até mesmo, para a sociedade. Esta não pode ser vista como um fim, mas um meio que ajude primeiro a forjar novos 
seres humanos. Precisamos dos conhecimentos técnicos, mas precisamos primeiro formar gente humana, seres críticos que entendam a realidade $\mathrm{e}$ que ajudem a transformá-la.

Hoje, temos uma crítica séria ao sistema educacional vigente; esse trabalha e forma meramente para o mercado e, muitas vezes, até mesmo o que deveria ser público é financiado pelo mercado. É preciso repensar a educação em outra lógica, respeitando as especificidades, trabalhando com a dimensão sociocultural, política e econômica, trabalhando, no nosso caso, com a realidade do campo, formando pessoas que contribuam com a melhoria ou transformação da nossa realidade.

O MST busca trabalhar desde as crianças, com a educação infantil, a educação de jovens e adultos, os cursos técnicos e de graduação. Nas várias escolas conquistadas ou nos cursos com que temos parcerias, buscamos, em conjunto, desenvolver essa nova proposta, pois estamos em um meio onde muitas questões têm a ver com as estruturas do Estado vigente, que tem outras propostas e objetivos a serem alcançados.

\author{
Álvaro Santin \\ E-mail: alvaro@mst.org.br \\ Célia Regina Vendramini \\ Professora do Centro de Ciências da Educação da UFSC \\ Doutora em Educação pela UFSCar \\ E-mail. cvendram@ced.ufsc.br
}

\title{
Sonia Maria Rummert
}

Professora da Faculdade de Educação da UFF

Doutora em Educação pela PUC-RJ

E-mail: rummert@uol.com.br 